\title{
Os efeitos do racismo na autoestima da mulher negra ${ }^{1}$
}

Rafaele Cristina de Souza Queiroz E-mail: rafaele.csq@gmail.com Universidade Federal do Amazonas, Manaus, Amazonas, Brasil

\section{RESUMO}

O racismo em relação à estética negra e à estrutura do cabelo negro crespo/cacheado têm impactos negativos na autoestima da mulher negra. Trata-se, neste estudo, dos efeitos do racismo na autoestima da mulher negra no que diz respeito à recusa do cabelo natural e às saídas para se enquadrar em um padrão estético racista. Foi realizado um estudo de natureza bibliográfica, em que se tem a predominância para a discussão das reflexões de Nilma Gomes, intelectual negra que norteia as reflexões deste artigo, para melhor interpretação dos termos e conceitos apresentados no decorrer das discussões aqui levantadas. O trabalho em questão é parte de uma etnografia realizada no evento Encrespa Geral Manaus, promovido pelo Instituto de Promoção Humana e Desenvolvimento Social e Cultural, em grupos de redes sociais administrados pelas membras do evento, que realizam atividades voltadas para a valorização da estética negra nestes grupos das redes sociais e com mulheres negras fora dessas esferas. Conta também com uma pesquisa quanti/qualitativa aplicada dentro dos grupos de mídias sociais.

PALAVRAS-CHAVE: Cabelo Crespo. Racismo. Identidade Negra. Autoestima. Ressignificação. 


\section{INTRODUÇÃO}

Este é um trabalho etnográfico que parte do pressuposto de que o cabelo crespo é uma expressão da identidade negra e, assim, proponho ouvir as narrativas de mulheres negras que passaram pelo processo de transição capilar. Nestas narrativas, percebo como o racismo e o preconceito racial afetou negativamente a autoestima dessas mulheres e como, para elas, vivenciar o ativismo de cabelo de mulheres negras ressignifica positivamente a identidade negra, fazendo com que sua autoestima se eleve. Portanto, o ativismo capilar é entendido como uma ação política de resistência, com a possibilidade de proporcionar um bem viver para as mulheres negras. Dando-se esta etnografia em dois ambientes: o virtual dentro dos grupos das redes sociais Facebook e Whatsapp, durante a realização do evento Encrespa Geral Manaus, no dia 2 de dezembro de 2017, na cidade de Manaus/Am. Porém, neste artigo se encontra apenas parte desta etnografia que se deu dentro do ambiente virtual, utilizando-se das mídias sociais para levantamento de informações. Esta etnografia foi realizada através da observação participante no grupo Encrespa Geral Manaus e redes sociais, o qual realiza ações voltadas para a valorização da estética negra e em grupos nessas mídias. Conta também com uma pesquisa quanti/qualitativa aplicada nesses espaços online.

A estética negra sofre ataques racistas desde muito tempo, tais ações podem ser nocivas para a saúde emocional de muitas mulheres negras, que são afetadas da infância à fase adulta, resultando na luta da mulher negra para existir com seu pertencimento racial. Em geral, no Brasil, ter o cabelo natural crespo é ser alvo de comentários pejorativos, propagandas e piadas racistas. Historicamente foi criado todo um arsenal de argumentos e estratégias para que o negro alisasse seu cabelo crespo, pois se entende que cabelo bom é cabelo liso e alinhado. O cabelo crespo, de acordo com esta concepção, tem aspecto de sujo, grotesco, bagunçado, ruim, é considerado um cabelo desproporcional e fora de uma estética padrão ditada pelas grandes marcas de cosméticos, revistas e mídia em geral.

A mulher negra internaliza essas imagens subjetivamente, propagandas e comentários a respeito de si, entendendo que o seu cabelo não é bonito como o que vê nas mídias, nas revistas, nas prateleiras de lojas de cosméticos e, dependendo do meio social que esta mulher está inserida, ouvirá comentários como: "porque você não alisa seu cabelo?", "amarra esse cabelo que ele está muito volumoso", "nossa, seu cabelo é muito ruim", "conheço produtos bons que podem melhorar isso aí". Com tal enxurrada de reprovações, a mulher negra poderá vir a alisar seus cabelos, fazer procedimentos químicos que possam causar reações alérgicas, queda e quebra de cabelo, corte químico entre outros efeitos os quais podem ser prejudiciais à sua saúde, tanto física quanto psicológica, podendo ser observado esses efeitos na autoestima destas mulheres, mediante às suas narrativas referentes às suas vivências com os seus cabelos crespos/cacheados.

Esses efeitos foram relatados pelas depoentes e também são descritos em blogs e sites de jornalismo ${ }^{2}$ que relatam os perigos dos cremes alisantes, pois alguns contém substâncias tóxicas como o formol, mesmo este sendo proibido desde 2009 no Brasil. Em uma matéria no site Estadão, Marcel Naves (2015), a Dermatologista Priscilla Kalizaki alerta que "[...] a exposição prolongada ao formol pode causar desde feridas na boca e narina a doenças mais graves, como câncer de faringe, traqueia e brônquios." 
Esta etnografia se atenta para os efeitos do racismo na autoestima da mulher negra, partindo do seu ponto de observação a estrutura capilar crespa/cacheada predominante em pessoas negras. Se propõe a refletir por meio das narrativas aqui presentes como uma estética padrão branca pode ser maléfica para a autoestima destas mulheres. $\mathrm{O}$ racismo é uma ferramenta agressiva aos corpos negros.

A internet tem um papel importante neste momento que é de levar informações e referências de pessoas que voltam a usar seus cabelos naturais, como blogueiras, atrizes, cantoras entre outras. Nesse sentido, a representatividade é importantíssima, levando várias mulheres a se integrarem a este movimento fazendo grupos de apoio e fóruns na internet, para ajudá-las e dar dicas para as que entram no processo de transição capilar ${ }^{3}$.

Com um público grande de pessoas voltando ao cabelo naturalmente crespo e cacheado, o mercado de cosméticos atenta-se e investe neste segmento. Os cabelos naturalmente crespos/cacheados se tornam motivos de muitas matérias na mídia ${ }^{4}$, nas revistas e as prateleiras aparecem com muitos produtos para essas estruturas capilares. A passos lentos as perguntas começam a mudar: "Por quê você não deixa seu cabelo encrespar?", "nossa, que volume maravilhoso tem seu cabelo!", "gostei do corte do seu cabelo". Isso trouxe um efeito positivo na autoestima da mulher negra, pois tais elogios, assim como a divulgação de mais produtos e o reconhecimento de outras pessoas com cabelos crespos, funciona como um reforço positivo em suas subjetividades.

Dessa forma, graças a tantas mulheres negras que incentivaram outras a saírem das algemas do alisamento capilar, é possível que elas percebam, assim, o quanto os cabelos crespos são lindos, dignos de serem livres de químicas. Mas ainda é possível se deparar com atitudes racistas, por isso, a existência de grupos de ativismo de cabelo crespo é importante como fenômeno social de enfrentamento ao racismo. Esses grupos proporcionam ações de afirmação da beleza da mulher negra, promovem encontros, mesas de debates e formações sociais, assim como fazem pressão nas mídias e nas empresas de cosméticos para buscarem integrar cada vez mais a estética negra. Tais ações, por fim, levam o combate ao racismo ao alcance de muitas pessoas.

\section{CABELO CRESPO: UMA EXPRESSÃO DA IDENTIDADE NEGRA.}

Não se tem um conceito único para identidade, um conceito predefinido e formado à respeito. No entanto, procuro neste trabalho usar as reflexões sobre identidade das quais Kabengele Munanga (1994, p. 177-178) trata:

\footnotetext{
A identidade é uma realidade sempre em todas as sociedades humanas. Qualquer grupo humano, através do seu sistema axiológico sempre selecionou alguns aspectos pertinentes de sua cultura para definir-se em contraposição ao alheio. A definição de si (autodefinição) e a definição dos outros (identidade atribuída) têm funções conhecidas: a defesa da unidade do grupo, a proteção do território contra inimigos externos, as manipulações ideológicas por interesses econômicos, políticos, psicológicos, etc.
}

Sendo assim, compreendo a relação de si com o outro na construção da identidade, pois "[...] nenhuma identidade é constituída no isolamento. Ao contrário é negociada durante a vida toda por meio do diálogo, parcialmente exterior, parcialmente interior, com os outros..." (JACQUES D`ADESKY apud 
GOMES 2005, p. 42). Se dando a construção da identidade em todas as esferas sociais, políticas, econômicas, psicológicas, culturais, sexuais e de gênero, não apenas pelo fenótipo. Guacira Lopes Louro (1999) enfatiza à respeito das multiplicidades das identidades:

Somos, então, sujeitos de muitas identidades e essas múltiplas identidades sociais podem ser, também, provisoriamente atraentes, parecendo-nos, depois, descartáveis elas podem ser, então, rejeitadas e abandonadas. Somos, desse modo, sujeitos de identidades transitórias e contingentes. Por isso as identidades sociais têm caráter fragmentado, instável, histórico e plural. (LOURO 1999 apud GOMES, 2005, p. 43)

Pensando identidade a partir da relação social com o outro, Lília Pereira (2012) pontua que a identidade negra se dá a partir de um processo coletivo, e afirma que a construção da identidade negra é formada "por meio de significados e representações dos atores sociais" (PEREIRA, 2012 p. 40). Ela não é inata ao indivíduo, mas sim construída nas relações e meios sociais. Neste sentido, a identidade negra acontece "como um movimento que não se dá apenas a começar do olhar de dentro, do próprio negro sobre si mesmo e seu corpo, mas também na relação com o olhar do outro, do que está fora" (GOMES, 2008, p. 9).

Ademais, a identidade étnico-racial negra no Brasil é construída no seio de grandes conflitos raciais. Carregar no corpo dados biológicos e culturais da identidade negra pode acarretar grandes conflitos raciais, que são subjetivamente negativos para a autoestima da mulher negra, sendo assim, o cabelo crespo é uma das expressões da identidade negra que sofre constantes ataques racistas. Pois "o cabelo, pode ser um dos caminhos para a compreensão da identidade negra em nossa sociedade" (GOMES, 2003, p. 174). Portanto, compreendo a construção da identidade negra a partir da afirmação de Nilma Gomes $(2008$, p. 9) como:

[...] construída historicamente em uma sociedade que padece de um racismo ambíguo e do mito da democracia racial. Como qualquer processo identitário, ela se constrói no contato com o outro, no constante com o outro, na negociação, na troca, no conflito e do diálogo.

Assim, pois, se dão as relações do outro com o cabelo crespo da mulher negra e de suas ações e olhares voltados à estética negra, o que torna essa relação problemática. A interferência do outro na relação da mulher negra com o seu cabelo afeta a sua autoestima. E como uma expressão da identidade negra o cabelo crespo é um marcador cultural e biológico dentre outros marcadores, como o corpo, o tom da pele, mas o aspecto tradado neste estudo como um marcador da identidade negra crespas/cacheadas. Segundo Gomes (2003, p. 174):

\footnotetext{
O cabelo é um dos elementos mais visíveis e destacados do corpo. Em todo e qualquer grupo étnico ele é tratado e manipulado, todavia a sua simbologia difere de cultura para cultura. Esse caráter universal e particular do cabelo atesta a sua importância como símbolo identitário.
}

O cabelo crespo, bem como o corpo do negro, é constituído para além de fenótipos biológicos, afirma Gomes (2008, p. 9): "são pensados pela cultura, [...] eles possibilitam a construção social, cultural, política e ideológica [...]", sendo assim é preciso pensar o ser negro em relação aos outros, em sociedade. O cabelo crespo é um dos marcadores da identidade negra no Brasil. No Amazonas, por 
exemplo, temos a predominância e referência da estrutura capilar indígena, que é marcante na população amazonense, refiro-me à estrutura capilar indígena lisa, escuro como a noite e brilhante como um diamante negro. Tendência essa que proporciona a curvatura dos cabelos das mulheres negras amazônicas a serem mais abertos, como cabelos de raízes lisas e extensão cacheada, mesmo não sendo um fator dominante.

É a partir da percepção e compreensão da identidade negra que esta etnografia trata o cabelo crespo da mulher negra como expressão identitária, e procura compreender de que maneira estas mulheres negras lidam com os seus cabelos crespos/cacheados, como os comentários preconceituosos de cunho racista atingem sua autoestima e de que forma os movimentos sociais negros, voltados para a estética negra constroem uma imagem positiva do ser negro. A sociedade vai assim construindo lentamente uma imagem positiva do negro através da valorização do cabelo crespo por meio dos movimentos sociais negros, resultando em um processo de ressignificação da identidade.

\section{O CABELO CRESPO É BOM, RUIM SÃO OS EFEITOS DO RACISMO NA AUTOESTIMA DA MULHER NEGRA.}

Como se amar, se aceitar e se ver positivamente no espelho se a sociedade te faz se sentir feia e fora dos padrões de beleza? Padrão de beleza este inalcançável por mulheres negras, pois é um padrão branco. Historicamente, o negro foi levado à negação de si: a colonização conseguiu implantar na mentalidade do negro brasileiro o sentimento de inferioridade, alimentando a visão negativa de si, através da imposição de uma cultura colonizadora. A cultura do embranquecimento foi uma ferramenta expressiva no genocídio da estética negra, e as mulheres negras foram as principais atingidas, pois são as que mais sofreram e vêm sofrendo com seus corpos, por causa do racismo.

Por racismo compreendo em Gomes (2005) como sendo "um comportamento, uma ação resultante da aversão, por vezes, do ódio, em relação a pessoas que possuem um pertencimento racial observável por meio de sinais, tais como: cor da pele, tipo de cabelo etc." (GOMES, 2005, p. 52). Essa aversão é violenta e atinge a subjetividade da mulher negra, que carrega consigo os sinais da negritude, principalmente mulheres negras mais retintas com os cabelos mais crespos, os ditos cabelos tipo $4 a, b, c^{5}$, afetando assim, como essa mulher se vê através do olhar do outro que está de fora interferindo em sua relação com o seu cabelo. Sendo o cabelo uma característica do corpo mais expressivo, além da cor da pele, torna-se um elemento fácil de comentários preconceituosos, os quais a mulher negra chega a internalizar subjetivamente, o que acaba afetando sua autoestima, aqui tratada como "construção social, na qual cada sujeito vai podendo construir-se, na medida em que se relaciona com os outros." (JULIO, 2011, p. 62).

Sempre é negado que o Brasil tem uma sociedade racista. Negam o racismo dizendo que vivemos em um país de democracia racial. Essa negação do racismo na sociedade brasileira só reafirma a existência do mesmo, pois ele se alimenta e se mantém da negação e invisibilidade do negro. A desigualdade racial e o racismo existem, basta recorrer aos dados estatísticos para localizar a posição do negro na sociedade brasileira. Diante disso, a pesquisa feita pela Heads Propaganda aponta 
que em 2015, nas propagandas e comerciais, apenas $1 \%$ das participantes são mulheres negras. Em 2017 este número teve um aumento significativo, passou para $21 \%$ de mulheres negras em comerciais. Esses números ainda são baixos, brancos ainda são a maioria a ocupar os espaços na mídia comercial. Hoje percebese um pequeno aumento de representatividade em relação às propagandas. É um passo a ser comemorado, porém, ainda se tem muito que conquistar.

Com a frequente ausência de representatividade e os ataques racistas à estética negra, a saúde emocional das mulheres negras é afetada, causando complexos de inferioridade, insegurança, baixa autoestima, ansiedade, depressão, a recusa de sua identidade negra e a busca para a aproximação com a estética do cabelo liso, através de procedimentos químicos e não químicos de alisamento. $\mathrm{A}$ antropóloga Gomes (2003) chama essa ação preconceituosa sobre o corpo, o cabelo e os ataques à identidade negra como "patrulhamento ideológico".

Através desta etnografia e dos depoimentos das mulheres negras é possível identificar em suas falas, como o racismo afetou a autoestima delas, e como o olhar do outro pode ser uma ação opressora sobre o corpo da mulher negra. 0 racismo mata emocionalmente e fisicamente. Como tratado nesta etnografia, a estrutura capilar da mulher negra e os efeitos do racismo em sua autoestima, comentários pejorativos como: cabelo ruim, feio, sujo, cabelo de bombril e desarrumado, são expressões genuínas do racismo. Gomes (2008, p. 9) destaca que:

\begin{abstract}
O cabelo do negro, visto como "ruim", é expressão do racismo e da desigualdade racial que recai sobre esse sujeito. Ver o cabelo do negro como "ruim" e do branco "bom" expressa um conflito. Por isso, mudar o cabelo pode significar a tentativa do negro de sair do lugar de inferioridade ou a introjeção deste. Pode ainda representar um sentimento de autonomia, expresso nas formas ousadas e criativas de usar o cabelo.
\end{abstract}

As mulheres negras com as quais tive contato, afirmavam que as pessoas que emitiam comentários racistas agiam "naturalmente", como se aquilo que elas falam de ruim sobre os seus cabelos fosse normal, sendo assim naturalizando o racismo por meio de comentários negativos. Tais comentários são perversos para autoestima destas mulheres.

Em alusão ao dia 20 de novembro, em que se comemora o Dia da Consciência Negra no Brasil, o site El País Brasil publicou um artigo intitulado Racismo não dá descanso e impacta a saúde e o trabalho dos negros no Brasil de Beatriz Sanz, que aponta que em:

\footnotetext{
Um estudo feito por pesquisadores da Universidade do Texas mostra que pessoas que sofreram com discriminação estavam sujeitas a desenvolver alcoolismo e depressão. Co-autora do estudo, a socióloga Trenette Clark diz que a discriminação tem efeitos semelhantes à perda do emprego ou à morte de um ente querido. (Sanz, 2017, online)
}

Ou seja, a ação do racismo vai para além de xingamentos verbais, não é apenas violência simbólica, e existe toda uma estrutura e uma relação de sofrimento e violência. Ainda sobre este sofrimento, na matéria de Beatriz Sanz (2017, online), a psiquiatra Noemi Kon firma: "obviamente que essa violência causa sofrimento psíquico" e mais, o racismo "pode fazer com que as pessoas se sintam menos qualificadas a ocupar determinados espaços na sociedade e a 
estabelecer relações amorosas de qualidade, por exemplo". É visível este sofrimento nos depoimentos das mulheres negras, as quais passaram a alisar seus cabelos, e também naquelas que resistiam a mantê-los naturais sem químicas para alisamentos ou técnicas que esticassem os fios crespos. Se reafirmar e manter os cabelos crespos é tido como um ato político e de resistência numa sociedade racista em que o negro é julgado pelo seu corpo, cabelo, a cor da pele e não pelo seu caráter.

A mulher negra lida com o racismo desde a infância na escola, tentando manter seu cabelo sempre "arrumado" na visão de um padrão que não the pertence. A dor de pentear, amarrar, fazer tranças e outros penteados, cria uma relação negativa entre a criança negra e seu cabelo, pois além de causar dor física pelo fato de penteá-los com força, amarrar apertado, horas sentada para fazer tranças, também há dor emocional ao ouvir palavras que são reforços negativos sobre a sua imagem e seu cabelo. Este olhar negativo de sua imagem pode ter proporções maiores durante a adolescência, uma fase de grandes eventos na vida humana.

Nessa linha, as depoentes se emocionam quando falam sobre a relação delas com os seus cabelos, desde que começaram a alisar até quando decidiram voltar à estrutura capilar natural, passando assim pela transição capilar que pode ser tida como um dos processos de ressignificação de sua identidade negra. É, muitas das vezes, durante a transição capilar que as mulheres negras se percebem enquanto negras, na busca e conexão com a sua identidade étnico/racial. Isso me faz lembrar Lélia Gonzalez, que afirma: “(...) a gente nasce preta, mulata, parda, marrom, roxinha dentre outras, mas tornar-se negra é uma conquista." (GONZALEZ, 1988 apud Cardoso, 2014, p. 973), no contexto amazonense poderíamos acrescentar também o termo "morena cor de jambo". Neste sentido se autodeclarar e se afirmar com mulher negra é muitas das vezes um processo de autoconhecimento, da relação com o outro e as experiências vividas na sociedade.

O encrespamento do cabelo é como um processo torna-se negra. Muitas das mulheres negras narram que estavam se descobrindo negras a partir da transição capilar. Para Ana Luiza Julio (2011, p. 67) "A busca da identidade negra é romper com o status quo e com todos os valores considerados como valores universais". E estas mulheres negras se juntam à outras que estão passando pelo mesmo processo, com o intuito de se fortalecerem e trocarem experiências relacionadas às suas vivências capilares. Muitas se engajam no ativismo negro relacionados à estética e posteriormente se engajam a outros locais de fala na busca de um bem viver para a população negra. É possível afirmar, observando as redes sociais, que nos últimos anos houve um crescimento de grupos de apoio nessas redes como canais no Youtube, grupos do Facebook, páginas de incentivo à transição capilar, com advento de um movimento de encrespamento do cabelo da mulher negra. $O$ engajamento nesses grupos é protagonizado por mulheres de diferentes realidades sociais e regionais, também por mulheres do ramo artístico que servem como representação social e funcionam como reforço positivo para aquelas que decidem parar de alisar seus cabelos. Um movimento em que as redes sociais são grandes responsáveis pela sua proporção e alcance de muitas mulheres negras que passam se amar e se aceitarem com suas raízes crespas naturais.

O mercado de cosméticos se atentou para este movimento e passou a produzir cada vez mais produtos para cabelos crespos/cacheados, tornando visível 
que o movimento de encrespamento tem grandes proporções e passou a ser um dos assuntos mais pesquisados na Internet.

\section{MULHERES NEGRAS E SUAS NARRATIVAS}

Foram obtidas narrativas de 39 mulheres, porém aqui constam apenas algumas, pelo fato de suas falas serem semelhantes. As perguntas foram direcionadas para mulheres residentes de Manaus, autodeclaradas pretas ou pardas, seguindo a classificação de identidades étnico-raciais do Instituto Brasileiro de Geografia e Estatística - IBGE. A média de idade dessas mulheres é de aproximadamente 27 anos, a mais nova com 17 anos e a mais velha com 48. Foram contatadas via redes sociais: Facebook e o Whatsapp. As mulheres tinham a possibilidade de responder as perguntas sem a interferência de terceiros, através de um link para o formulário, sendo assim, se expressavam via texto, que estarão nesta etnografia sem correção ortográfica e gramatical, sem que isso interfira na compreensão do que as depoentes relatam.

Na primeira variável qualitativa, a pergunta é se a mulher sempre utilizou o cabelo naturalmente crespo/cacheado, e $80 \%$ das mulheres responderam que não, ou seja, isso significa que em alguma vez de sua vida essa mulher já relaxou, alisou ou fez algum procedimento químico que mudasse a sua estrutura capilar. A maioria já alisou ou relaxou os cabelos, e muitas dessas mulheres fizeram esse procedimento cedo, como aponta a variável: "com qual idade começou a alisar os cabelos?". As respostas remetem a infância, entre 7 e 10 anos, quando a criança enfrenta muitas situações negativas referentes ao seu cabelo, que carregará consigo por muito tempo, e isso ocorre na escola ${ }^{6}$ que a criança negra é alvo de comentários racistas, os quais levarão à construção negativa de sua imagem. Duas dessas mulheres começaram a alisar seus cabelos aos quatro anos de idade, e com químicas. Referente à motivação que levaram essas mulheres a alisarem seus cabelos, destacamos:

A.M.: “Apelidos na escola.

R.: Por achar o meu cabelo feio, porque não parecia com o cabelo das outras meninas que eram liso.

H.: As piadas sobre ele, os comentários.

A.K.: As pessoas diziam que ficaria bonito. Ajeitaria.

A.R.: Queria ter o cabelo liso, porque era sinônimo de cabelo bonito. Achava que meu cabelo cacheado era feio e desarrumado.

A.: Não me sentia bonita. Pressão estética e social." (DEPOIMENTOS DOS FORMULÁRIOS DO GOOGLE, 03/11/2017)

As motivações que levaram essas mulheres a alisarem seus cabelos eram várias, algumas delas relatadas acima. Nos relatos sempre estava em jogo a interferência do outro frente à estrutura capilar.

As técnicas de alisamento utilizadas são diversas: produtos químicos de alisamento capilar, que contém agentes químicos para esticar o fio crespo/cacheado, chapinha e secador quente. E fizeram esses procedimentos por muito tempo, entre 10 a 16 anos alisando seus cabelos, utilizando produtos 
químicos que entram em contato com o couro cabeludo, e ao longo do tempo poderão apresentar efeitos prejudiciais à saúde capilar e do corpo.

Como dito anteriormente neste estudo, o uso de química de alisamento capilar pode causar malefícios à saúde. Perguntei àquelas que alisavam seus cabelos com química de alisamento capilar se chegaram a passar mal alguma vez por causa da química em seus cabelos, e $40 \%$ afirmaram que sim. Além de passar mal, as depoentes afirmam que seus cabelos caíram, dentre elas, seis afirmaram essa reação, nove afirmaram que os seus cabelos quebraram e nove tiveram ambas as agressões em seus fios por causa do uso da química de alisamento.

Busquei ouvi-las sobre as suas relações com os seus cabelos e a relação dos/com os outros. Esse ponto é um pouco delicado, em que se percebe como o outro interfere na maneira em que elas se viam. Sobre o olhar do outro sobre os cabelos naturais dessas mulheres negras, a maioria afirma que já ouviram comentários pejorativos, que remetem ao sentimento negativo sobre o cabelo crespo/cacheado. Os comentários relatados por elas são:

R.T.: "Cheguei a ouvir da pedagoga da escola onde fiz o ensino médio, ela me chamava de "cabeluda" no termo pejorativo, e ouvi colegas me chamando de "cabelo de Bombril", mas o mais incrível foi que nesta escola (ressaltando que é uma escola no interior do Amazonas) todas usavam cabelo liso, e tinha várias meninas de cabelo cacheado mais que alisavam ou mantinham ele sempre preso, e mesmo com o preconceito que sofri depois de um tempo várias meninas passaram a usar o cabelo cacheado de forma livre e reconhecendo que seus cabelos são lindos como são! Inclusive a pedagoga da escola também!

L.G.: Cabelo de vassoura, fua, Valderrama, cabelo de Bombril.

R.A.: Coisas do tipo: "seu cabelo parece um capacete", ou "cabelo crespo parece fuá" e o mais frequente são "você está linda de cabelo natural, mas quando vai voltar a alisar?

J.K.: Agora seu cabelo vive bagunçado, cabelo ruim, nem parece que é profissional com esse cabelo ele te dá aspecto de pessoa q não tem responsabilidade.

D.P.: Mana, foram tantos os de sempre, cabelo de bombril, macaca e por aí vai. Mas especialmente me apelidaram de "leão", pois estava rolando um propagando na tv que tinha um leão e depois de usar o produto capilar, o leão ficava lisinho; se eu conhecesse Caetano talvez não tivesse sofrido tanto... "gosto muito de te ver, leãozinho.

A.C.: cabelo despenteado, mal arrumado, cabelo ruim" (DEPOIMENTOS DOS FORMULÁRIOS DO GOOGLE, 03/11/2017)

Esses comentários são altamente ofensivos à autoestima destas mulheres, pois são expressões racistas e uma maneira de inferiorizar a estética negra.

Foram também questionadas se tinham passado pela transição capilar (o período em que deixam de usar produtos químicos de alisamento para que as raízes naturais cresçam). Um número significativo afirma que sim, passaram pela transição. Em porcentagem, isso significa que $75 \%$ já passaram por esse processo. A transição capilar é um período delicado em que os cabelos naturais crescem e a raiz vão ficando mais volumosas, com a extensão do cabelo mais fina, muitas mulheres negras que passaram pela transição relatam que foi um período doloroso, pelo fato de não se sentirem bonitas e sempre usarem os cabelos 
amarrados para evitar comentários dos outros sobre os seus cabelos. Tais comentários descritos por elas na pergunta: "Qual foi a reação das pessoas ao saberem que você parou de alisar o cabelo?”, são:

M.F.: "Que o meu cabelo Tava cada dia pior, mais bagunçado e ridículo.

J.: Que eu não teria forças para continuar por muito tempo pois ficaria horrível.

R.A.: Recebi, mas de forma velada. Pensavam que era algo passageiro, algo que duraria o tempo para reparar os danos e pudesse voltar para a química. Morria de rir com as caras de horrorizados quando me ouviam falar que não alisaria mais.

J.S.: Diziam q já não bastava eu ser negra de pele escura, ter cabelo crespo já era demais.

J.K.: Que agora ficaria c o cabelo ruim de novo.

L.G.: Que cacheado eu ficava feia e que preferiam eu de cabelo liso." (DEPOIMENTOS DOS FORMULÁRIOS DO GOOGLE, 03/11/2017)

As mulheres passam por dias, meses e até mesmo anos sem alisar seus cabelos naturais, deixando eles crescerem naturalmente sem cortar, coexistindo a parte do cabelo liso e a parte crespa. Durante esse tempo eram alvos de racismo sobre a estrutura capilar desse período. As depoentes responderam à pergunta: "Durante a sua transição capilar ouviu comentários pejorativos?":

H.C.: "Vai alisar isso, metade do cabelo liso outra pixaim, isso tá ridículo

J.S.: Que cabelo crespo não ia ficar bem em mim e que crespo é ruim, duro

M.F.: Quando eu ia arrumar o cabelo de volta? A.S. Como vc aguenta? Não vai arrumar.

J.: O que eu tinha feito com o meu cabelo para ficar parecendo com bombril" (DEPOIMENTOS DOS FORMULÁRIOS DO GOOGLE, 03/11/2017)

Por outro lado, tiveram também reações positivas, comentários ditos por elas como:

A.: Que bom que parou de alisar, bem melhor assim, com volumão. Foi algum dos comentários que ouvi.

P.C.: A maioria estranhou, mas apoiaram.

J.S.: Algumas pessoas diziam q eu ficava melhor de cabelo natural.

A.S.: Incentivavam o uso de tranças e turbantes...

A.S.: Legal, você tem que assumir suas raízes." (DEPOIMENTOS DOS FORMULÁRIOS DO GOOGLE, 03/11/2017)

Para algumas, passar pela transição capilar com duas texturas de cabelo não foi uma boa experiência. Elas relatam que foi um "momento de baixa autoestima" 
ou, por conta da espera, até cortar a parte lisa e deixar apenas o cabelo natural, "foi difícil porque tem que esperar com paciência até se sentir preparada para cortar". Após a transição capilar vem o big chop ( no português, grande corte), que pode ser considerado um rito de passagem com uma grande carga emocional que ele apresenta às mulheres negras que passaram a ter suas raízes naturais, e o que o "b.c" representa dentro dos grupos das redes sociais nos quais essas mulheres trocam dicas de cuidados capilares. O big chop, como já dito anteriormente, é o grande corte que retira toda a parte do cabelo com química de alisamento, deixando apenas os cabelos naturais. Sobre este momento, perguntei: "Ao fazer o big chop qual foi a sua reação e como você se sentiu?".

P.C.: "Eu chorei muito. De felicidade, passei a me reconhecer e me conhecer como uma mulher negra.

R.T.: Foi incrível eu estava morrendo de medo mais quando vi o resultado amei.

A.K.: Eu amei o corte diferente, simultaneamente não conseguir prender me agoniava.

A.C.: Eu realizei o meu big chop, e foi libertador porque consegui ver de fato o formato do meu cabelo.

C.F.: LIBERDADE, eu mesma cortei meu cabelo e no início cortei tipo Chanel... depois foi assumido minha identidade, com a ajuda de finalizadores, linhas para transição, tiaras e outros.

R.L.: Foi revigorante. Libertador.

A.R.: Ah foi uma sensação de libertação. Como se tivesse começando uma nova fase da vida. Porque aprendi muitas coisas sobre o meu cabelo que não sabia antes. É uma questão também de auto aceitação. De se descobri, de se achar bonita sem se importar com padrões de beleza dos quais antes eu era escrava." (DEPOIMENTOS DOS FORMULÁRIOS DO GOOGLE, 03/11/2017)

O sentimento de liberdade após o big chop é uma das principais respostas. A sensação de estar livre de passar horas no salão para esticar os cabelos, de ficarem horas fazendo chapinha, o fato do cabelo estar natural, livre de químicas é uma sensação boa para essas mulheres. A transição capilar e o big chop tem grande contribuição no processo de ressignificação da identidade negra, pois aproxima a mulher negra de sua ancestralidade. Os outros também tiveram reação após o big chop dessas mulheres, tanto de maneira positiva como negativa:

A. K.: "Que ficou bonito, e que estava fofo.

R.A: Que eu era uma "inspiração", que viam uma nova pessoa, bem mais poderosa e bonita.

A.R: Que eu era corajosa por cortar o cabelo tão curto. Porque infelizmente na nossa sociedade (no mundo todo) a questão de ser mulher, de ser feminina está muito ligada ao cabelo comprido. Então quando você opta por usar um cabelo curto as pessoas te olham estranho, questionam inclusive a tua sexualidade, sendo que uma coisa não tem nada a ver com a outra. 
R.A.: Se não tinha vergonha de parece menos feminina, ou sexy... Coisas do tipo!

A.C.: como estava curto, achavam que parecia masculinizada." (DEPOIMENTOS DOS FORMULÁRIOS DO GOOGLE, 03/11/2017)

Referente à mudança na autoestima após o big chop e a volta aos cabelos crespos, há uma mudança significante em como esta mulher se vê. Isso é bastante perceptivo nos rostos dessas mulheres negras, principalmente nas rodas de conversas que ocorreram no Encrespa Geral 2017 e também em suas narrativas. Quando pergunto a elas se ocorreu alguma mudança em sua autoestima após voltarem a usar seus cabelos naturalmente crespos/cacheados, elas afirmam que:

P.C.: “Certeza, minha autoestima só engrandeceu, me sentir bem melhor, me sentir bonita.

I.B.: Me senti uma pessoa melhor, menos preocupação com chapinha e com chuva, me sinto linda.

A.K.: Me sinto mais empoderada, autêntica, confiante.

R. A.: A maior é questão da confiança com a autoimagem. Antes buscava seguir padrões e mesmo toda "na moda" não me sentia bonita. Achava que não ficava bem o suficiente para atrair a atenção ou os elogios. Eu senti essa mudança principalmente depois do BC, em que pude me ver um "mulherão da p*\$@" mesmo não tendo o cabelão que desejava por décadas.

G. R.: Foi a primeira vez em anos que me senti bonita de verdade." (DEPOIMENTOS DOS FORMULÁRIOS DO GOOGLE, 03/11/2017)

Pedi para que elas falassem sobre as suas atuais relações com os seus cabelos naturais crespos/cacheados, e como se sentiam ao se olharem no espelho. As frases resumem sentimentos e refletem a mudança pessoal para elas:

R.P.: Melhor que antes.

L.G.: Temos um relacionamento muitooooooooooo sério, e eu o amo do jeitinho que ele é. Satisfatória, utilizo produtos cosméticos para cabelos crespos e cacheados.

E.S.: Maravilhosa. Um amor íntimo e intenso.

A.M.: É saudável! Já não é mais o centro das minhas preocupações.

P.C.: Maravilhosa, orgulho total.

J.S.: É boa, amo meu cabelo, mas também adoro tranças, então estou experimentando usá-lo de outras maneiras, passei a usar tranças pra não ficar ansiosa pra ele crescer mais rápido, pq ele demora a crescer, mas eu acabei meio q viciando em tranças, gosto muito mesmo, preciso inclusive dar um tempo pra cuidar das madeixas Maravilhosa, muitos apreciam meus cachos naturais" (DEPOIMENTOS DOS FORMULÁRIOS DO GOOGLE, 03/11/2017) 


\section{CONSIDERAÇÕES FINAIS}

A identidade é construída no meio do convívio social dos sujeitos e na relação com o outro. A identidade negra no Brasil foi historicamente construída através da negação da humanidade do negro, na construção da inferioridade em relação ao branco colonizador. O cabelo crespo é essencialmente uma expressão da identidade negra que sofreu e sofre com o preconceito racial, que pode levar os indivíduos à recusa de suas raízes crespas, indo à busca da estrutura capilar similar à de seus opressores. Desta forma, a estética eurocêntrica se torna uma arma de opressão sobre os corpos e os cabelos crespos da mulher negra, que tenta se enquadrar ao padrão de estética branca, sem perceber o quanto foi influenciada, por considerarem o cabelo crespo como ruim, sujo e duro.

Com a etnografia virtual foi possível constatar que as mulheres negras muitas vezes subjetivam os comentários racistas, sofrendo uma violência em suas autoestimas, não se vendo como bonitas com os seus cabelos naturais crespos, levando-as a realizarem procedimentos químicos que podem ser maléficos à saúde, por terem substâncias tóxicas ao corpo humano. Nos diálogos com as mulheres negras é possível perceber como o racismo afeta a autoestima das mesmas, porém, na contemporaneidade e com o surgimento de movimentos negros voltados para valorização da estética negra, essa realidade vem se reformulando. Mulheres negras se unem em prol de ressignificarem a identidade negra, ou seja, propõem ações que visam o combate ao genocídio estético negro, como expressão disso o ativismo de cabelo. Foi possível entender, assim, várias fases da ressignificação do ser negro através do encrespamento, como a transição capilar, o big chop, que para muitas delas é um momento carregado de emoções e sentimentos bons, pois a volta às raízes crespas livres das químicas é por elas almejada.

O trabalho de ativismo de cabelo atingiu muitas mulheres negras, levando sua filosofia da volta ao cabelo crespo, como também mobilizou o mercado de cosméticos para a produção e ofertas de produtos específicos para esses cabelos. A mulher negra passou a se ver cada vez mais nas mídias, com as propagandas de produtos para o cabelo crespo, assim como artistas também encrespando suas raízes. A estética passa a ter significados políticos e de resistência, pois manter os cabelos crespos naturais é para além da estética, um ato de resistência e afirmação da identidade negra. O cabelo crespo não é apenas uma expressão corpórea genética do negro, é um elemento de resistência, e o encrespamento dos cabelos (transição capilar) é um rito de passagem em que o big chop é o ápice desse rito, que leva as mulheres negras para uma nova fase de suas vidas e de descobrimento de sua identidade étnico/racial, construindo novos significados ao ser negra.

E como canta o rapper Rincon Sapiência: "Faço questão de botar no meu texto que pretos e pretas estão se amando." 


\title{
The effects of racism on black women's self- esteem
}

\begin{abstract}
Racism in relation to black aesthetics and curly black / curly hair structure have negative impacts on black women's self-esteem. This study is about the effects of racism on the selfesteem of black women in what is said to refuse natural hair and exits to fit a racist aesthetic pattern. It was carried out a study of bibliographical nature where the predominance for the discussion is the reflections of Nilma Gomes, for a better interpretation of the terms and concepts presented in the research. The work in question is part of an ethnography held at the Institute for Human Promotion and Social and Cultural Development Encrespa Geral Encrespa, which carries out actions throughout Brazil, and this ethnography is Encrespa Geral Manaus, which carries out activities aimed at enhancing aesthetics black and social media groups and with black women outside these spheres. It also has quantitative / qualitative research applied within social media groups.
\end{abstract}

KEYWORDS: Curly hair. Racism. Black identity. Self esteem. Re-signification.

\section{Los efectos del racismo en la autoestima de la mujer negra}

\author{
RESUMEN
}

El racismo en relación a la estética negra y la estructura del cabello negro crespo / cacheado tiene impactos negativos en la autoestima de la mujer negra. Se trata en este estudio de los efectos del racismo en la autoestima de la mujer negra en lo que se dice el rechazo del cabello natural y las salidas para encuadrarse en un patrón estético racista. Se realizó un estudio de naturaleza bibliográfica donde se tiene la predominancia para la discusión las reflexiones de Nilma Gomes, para mejor interpretación de los términos y conceptos presentados en la investigación. El trabajo en cuestión es parte de una etnografía realizada en el Instituto de Promoción Humana y Desarrollo Social y Cultural, en el que realiza acciones en todo Brasil, y el de esta etnografía es el Encrespa General Manaus, que realiza actividades dirigidas a la valorización de la estética negra y en grupos en los medios sociales y con mujeres negras fuera de esas esferas. También cuenta con una investigación cuantitativa / cualitativa aplicada dentro de los grupos de medios sociales.

PALABRAS CLAVE: Pelo CRESPO. Racismo. Identidad NEGRA. Autoestima. Reframing 
${ }^{1} \mathrm{O}$ presente trabalho foi realizado com o apoio da Universidade Federal do Amazonas-UFAM por meio do Programa Institucional de Bolsas de Iniciação Científica (PIBIC).

${ }^{2}$ https://www.saudedica.com.br/os-4-efeitos-colaterais-do-alisamento-docabelo/;

https://g1.com/Noticiais/Brasil?0,,MUL142355598,00OS+PERIGOS+DO+ALISAME NTO+DE+CABELO.html;

https://mdemulher.abril.com.br/cabelos/os-perigos-causados-pelo-formol-dosalisamentos-decabelo/amp;

https://saúde.estadao.com.br/noticiais/geral,mesmo-proibido-formol-e-vendidoem-sp-imp-,1655797

${ }^{3}$ Transição capilar é deixar de usar produtos químicos para alisar o cabelo, e parar de fazer procedimentos que alisam os fios crespos. A transição capilar é a saída do cabelo quimicamente tratado para o cabelo natural. É voltar às raízes crespas.

${ }^{4}$ https://www.geledes.org.br/transicao-do-alisamento-para-o-cabelo-naturalpode-ser-feita-semtrauma6/\#axzz3ZGhN90wh; http://g1.globo.com/bemestar/noticia/2015/09/como-manter-os-cabeloscacheados-e-saudaveis-vejadicas.html; https://unicap.br/webjornalismo/revoluçãocrespa/site/index.php/2015/10/22/m ercado/ https://g1.globo.com/sao-paulo/noticia/2016/08/mulheres-dao-adeusao-alisamento-assumem-cachos- e-oorgulho-crespo.amp; https://noticiais.r7.com/rio-de-janeiro/rj-record/videos/moda-e-atitude-cabeloscrespo-e-cacheadosestao-em-alta-10082017

${ }^{5}$ Os cabelos têm classificações que vão desde os tipos 2 a 4, em que os cabelos classificados como 2 são os cabelos lisos a levemente ondulados, os cabelos 3 são os cabelos cacheados e levemente crespos, e os cabelos 4 são os crespos e crespíssimos. Essa classificação se dá principalmente no meio do mercado de produtos capilar, pois os produtos se diferenciam conforme a curvatura de cada cabelo.

6"A escola também se encontra a exigência de "arrumar o cabelo", o que não é novidade para a família negra (...) Em alguns momentos, cuidado dessas mães não consegue evitar que, mesmo apresentando-se bem penteados e arrumadas, a criança negra deixa de ser alvo das piadas e apelidos pejorativos no ambiente escolar..." (GOMES, 2002, p. 45)

7"Mesmo que reconhecemos que a manipulação do cabelo seja uma técnica corporal e um comportamento social presente nas mais diversas culturas, para o negro, e mais especificamente para o negro brasileiro, esse processo não se dá sem conflitos. Estes embates podem expressar sentimento de rejeição, aceitação, ressignificação e, até mesmo, de negação ao pertencimento étnico/racial." (GOMES, 2012, p. 44) 


\section{REFERÊNCIAS}

BRASIL. LEI № 7.716, DE 5 DE JANEIRO DE 1989. Disponível em: http://www.planalto.gov.br/ccivil_03/leis/L7716.htm. Acesso em: 05 abr. 2017.

CARDOSO, Cláudia Pons. Amefricanizando o feminismo: o pensamento de Lélia Gonzalez. In: Estudos Feministas, Florianópolis, v. 22, n. 3, p. 965-986, set.-dez., 2014.

GELEDÉS, Instituto da Mulher Negra. Ativismo de Cabelo. 23 jun. 2014. Disponível em: http://www.geledes.org.br/ativismo-de-cabelo/\#gs.hkrRem4. Acesso em: 29 mar. 2017.

GELEDÉS. O que cabelo tem ver com racismo. 14 jun. 2014. Disponível em: http://www.geledes.org.br/o-que-cabelo-tem-ver-com-racismo/. Acesso em: 20 mar. 2017.

GOMES, Nilma Lino. Sem perder a raiz: Corpo e Cabelo como símbolo de identidade negra. Belo Horizonte. Autêntica 2a ed, 2008.

GOMES, Nilma Lino. Alguns termos e conceitos presentes no debate sobre relações raciais no Brasil: Um breve discursão. In: Educação antis-racista: caminhos abertos pela lei Federal no 10.639/03. Brasília: Ministério da Educação, Secretária de Educação Continuada, Alfabetização e Diversidade, 2005.

GOMES, Nilma Lino. Educação, identidade negra e formação de professores/as: um ol har sobre o corpo negro e o cabelo crespo. Educação e Pesquisa, v. 29, n. 1, p. 167-182, 2003.

GOMES, Nilma Lino. Trajetória escolares, corpo negro e cabelo crespo: reprodução de estereótipos ou ressignificação cultural? Revista Brasileira de Educação, n. 2, Set/Out/Nov/Dez, 2002.

JULIO, Ana Luiza. Por uma visão psicossocial da autoestima de negros e negras. Protestantismo em Revista, São Leopoldo, RS, n. 24, 2011.

MUNANGA, Kabengele. Identidade, cidadania e democracia: algumas reflexões sobre os discursos antis-racistas no Brasil. In Resgate, n.6, 1994.

NAVES, Marcel. Mesmo proibido, formol é vendido em São Paulo. Estadão. São Paulo: Grupo Estado, 2015. Disponível em: $<$ http://saude.estadao.com.br/noticias/geral,mesmo-proibido-formol-evendidoem-sp-imp-,1655797>. Acesso em: 23 Jan. 2018.

PEREIRA, Lília Campos. A construção da identidade da mulher negra no Brasil. $2012 . \quad$ Disponível em: revistas.umce.cl/index.php/Comunicaciones/article/download/653/632/. Acesso em: 02 Abr. 2017. https://www.youtube.com/watch?v=vau8mq3KcRw. Acesso em: 05 de jul. 2019. 
SANZ, Beatriz. Racismo não dá descanso e impacta a saúde e o trabalho dos negros no Brasil. EL PAís. 20 nov. 2017. Disponível em: <http://brasil.elpais.com/brasil/2017/11/17/politica/1510954056_774052.html> Acesso em: 01 de dez. 2017.

Recebido: 30/01/2019

Aprovado: 24/06/2019.

DOI: $10.3895 /$ cgt.v12n40.9475.

Como citar: QUEIROZ, Rafaele Cristina de Souza. Os efeitos do racismo na autoestima da mulher negra. Cad. Gên. Tecnol., Curitiba, v. 12, n. 40, p. 213-229, jul./dez. 2019. Disponível em:

https://periodicos.utfpr.edu.br/cgt. Acesso em: XXX.

Correspondência:

Rafaele Cristina de Souza Queiroz

Av. Don Jacson Damasceno, 907, conjunto João Paulo, Nova cidade, Manaus, Amazonas, Brasil.

Direito autoral: Este artigo está licenciado sob os termos da Licença Creative Commons-Atribuição 4.0 Internacional.

\section{(c) (1)}

